\title{
Effect of Body Position on Skin Perfusion Pressure in Patients With Severe Peripheral Arterial Disease
}

\author{
Norihiko Shinozaki, MD, PhD
}

\begin{abstract}
Background: Skin perfusion pressure (SPP) has been shown to be useful in the assessment of the severity of peripheral arterial disease (PAD), and ulcers can be cured when the SPP is $\geq 30-40 \mathrm{mmHg}$. The purpose of this study was to determine the best body position for measuring SPP in patients with severe PAD.
\end{abstract}

\begin{abstract}
Methods and Results: We studied 24 limbs of 18 patients with PAD whose SPP was $\leq 40 \mathrm{mmHg}$. After patients had been resting supine for $10 \mathrm{~min}$ (Position I), their SPP was measured at the dorsum of the foot with a laser Doppler probe. Following measurement in the supine position, SPP was measured in the sitting position after the foot had been extended horizontally for $10 \mathrm{~min}$ (Position II), and in the sitting position after the foot had been lowered vertically for $10 \mathrm{~min}$ (Position III). SPP increased significantly from Position I to Positions II and III $(25.3 \pm 10.9 \mathrm{mmHg}$, $40.6 \pm 12.7 \mathrm{mmHg}$, and $73.4 \pm 17.7 \mathrm{mmHg}$, respectively; $\mathrm{P}<0.0001)$. In all patients, SPP values exceeding $30 \mathrm{mmHg}$ were obtained in Position III.
\end{abstract}

Conclusions: The best SPP values were obtained in Position III, which is the ideal position for peripheral arterial circulation in patients with severe PAD. (Circ $J$ 2012; 76: 2863-2866)

Key Words: Body position; Critical limb ischemia; Peripheral arterial disease; Skin perfusion pressure

V arious methods have been used to objectively evaluate ischemic limbs and it has been suggested that healing of trophic lesions is impossible if the skin perfusion pressure (SPP) is $<30-40 \mathrm{mmHg}$. ${ }^{1-5}$

SPP measurement was first reported in $1970 .{ }^{6}$ Initially, the blood pressure at the capillary vascular bed was measured by topically injecting a radioactive substance and applying pressure with a blood pressure monometer. This method, however, was not widely used because of its high cost, complexity and invasiveness. Later, a laser Doppler technique for measuring SPP was established as a method of evaluating skin tissue viability. ${ }^{78}$ Because very low levels of SPP can be measured more simply, less invasively, with higher reproducibility, and in a shorter time by this method, it is widely used. This method is especially useful for patients with severe calcification of the arterial walls, in whom ankle and toe pressure is not reliable. It is mainly used to determine the level of amputation of ischemic limbs when it is difficult to save a limb, or to predict the prognosis of ulcer healing. ${ }^{1-5}$ It has been reported that viability is poor if the SPP is $30-40 \mathrm{mmHg}$ or below. ${ }^{1-5}$ However, there are no data on the relationship between body position and SPP.

In the present study, we measured the SPP of patients with severe peripheral arterial disease (PAD) while they were in various positions to determine the ideal position to improve the SPP values.

\begin{abstract}
Methods
Study Population

For this study, 24 limbs of 18 patients with PAD ( 9 males, 9 females; age 60-90 years, average: $76.5 \pm 8.3$ years) whose SPP was $<40 \mathrm{mmHg}$ were enrolled. Written informed consent was given by each subject after a detailed explanation of the purpose and procedures of this study. The protocol was approved by the Ethical Panel of Naganoken Koseiren Shinonoi General Hospital.
\end{abstract}

\section{SPP Measurements}

After patients had rested supine for 10 min (Position I, Figure 1A), the SPP was measured at the dorsum of the foot using LASERDOPP (Vasamedics, St. Paul, MN, USA) with a laser Doppler probe. The laser Doppler flow sensor was secured within the bladder of the blood pressure cuff, which contained a transparent polyvinyl chloride window, so that low measurements could be made during cuff inflation and deflation. The pneumatic cuff was first inflated to a suprasystolic pressure. At this pressure, the laser Doppler flux was less than 0.1 volume percent. The cuff was stepwise deflated in $10 \mathrm{mmHg}$ decrements to $50 \mathrm{mmHg}$ and then in $5 \mathrm{mmHg}$ decrements to below $50 \mathrm{mmHg}$. The pressure was maintained for $15 \mathrm{~s}$ at each pressure interval. Deflation was continued until 2 consecutive increases in laser Doppler scan

Received April 27, 2012; revised manuscript received June 19, 2012; accepted July 17, 2012; released online August 11, 2012 Time for primary review: 16 days

Department of Cardiology, Tokai University School of Medicine, Isehara; Department of Cardiology, Naganoken Koseiren Shinonoi General Hospital, Nagano, Japan

Mailing address: Norihiko Shinozaki, MD, PhD, Department of Cardiology, Tokai University School of Medicine, 143 Shimokasuya, Isehara 259-1193, Japan. E-mail: shinori3@ tokai-u.jp

ISSN-1346-9843 doi:10.1253/circj.CJ-12-0562

All rights are reserved to the Japanese Circulation Society. For permissions, please e-mail: cj@j-circ.or.jp 
A

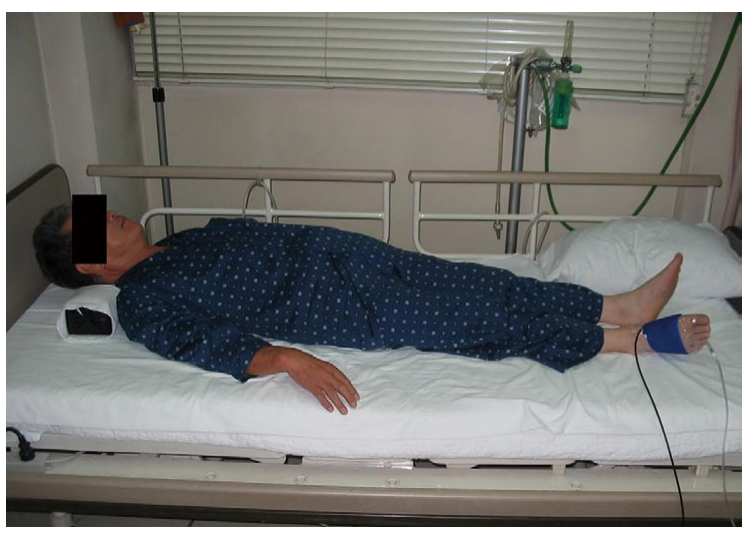

B

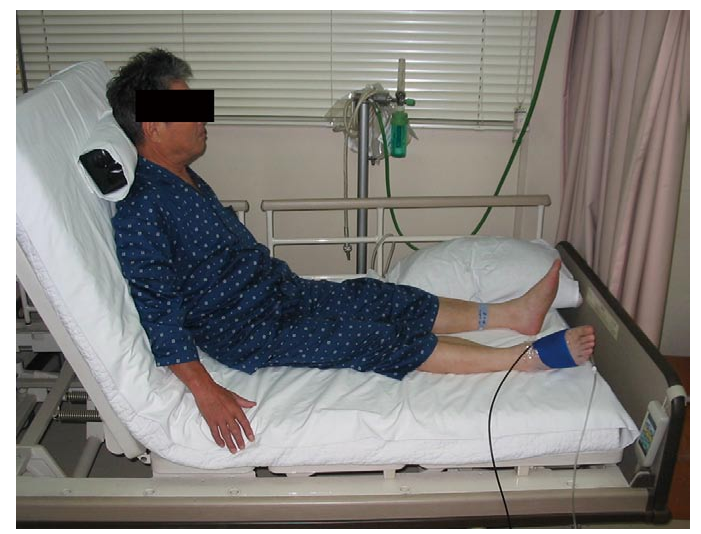

C

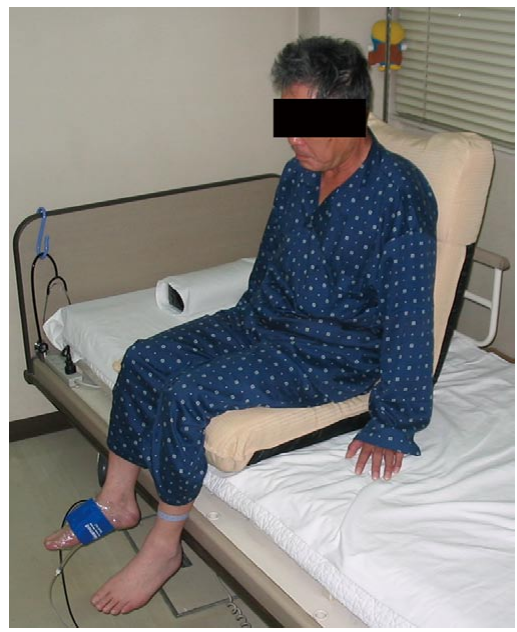

Figure 1. Patients' positions during measurement of skin perfusion pressure (SPP). Position I is lying supine (A), Position II is sitting with the foot extended horizontally (B) and Position III is sitting with the foot lowered vertically (C).

\begin{tabular}{|lc|}
\hline \multicolumn{2}{|l|}{ Table. Patients' Clinical Characteristics } \\
Age & $76.5 \pm 8.3$ years \\
Males & $9(50 \%)$ \\
Fontaine III/IV & $15(63 \%) / 9(37 \%)$ \\
Ankle-brachial index & $0.42 \pm 0.24$ \\
Diabetes & $11(61 \%)$ \\
Hypertension & $13(72 \%)$ \\
Dyslipidemia & $6(33 \%)$ \\
Current smoker & $8(44 \%)$ \\
Hemodialysis & $8(44 \%)$ \\
\hline
\end{tabular}

flux were noted. The first increase in the laser Doppler output represents the initiation of blood flow into the regional microcirculation and was taken to be the foot SPP. Following measurement in the supine position, SPP was measured with the patient in the sitting position after the foot had been extended for $10 \mathrm{~min}$ (Position II, Figure 1B) and after the foot had been lowered for $10 \mathrm{~min}$ (Position III, Figure 1C).

\section{Statistical Analysis}

Continuous variables are expressed as mean \pm standard devia-

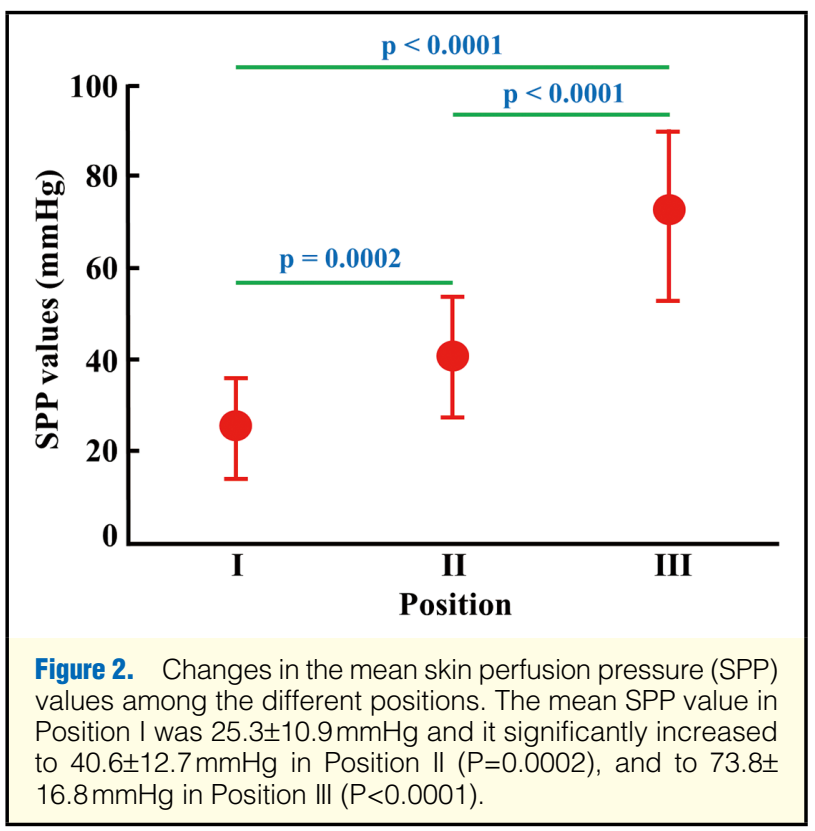



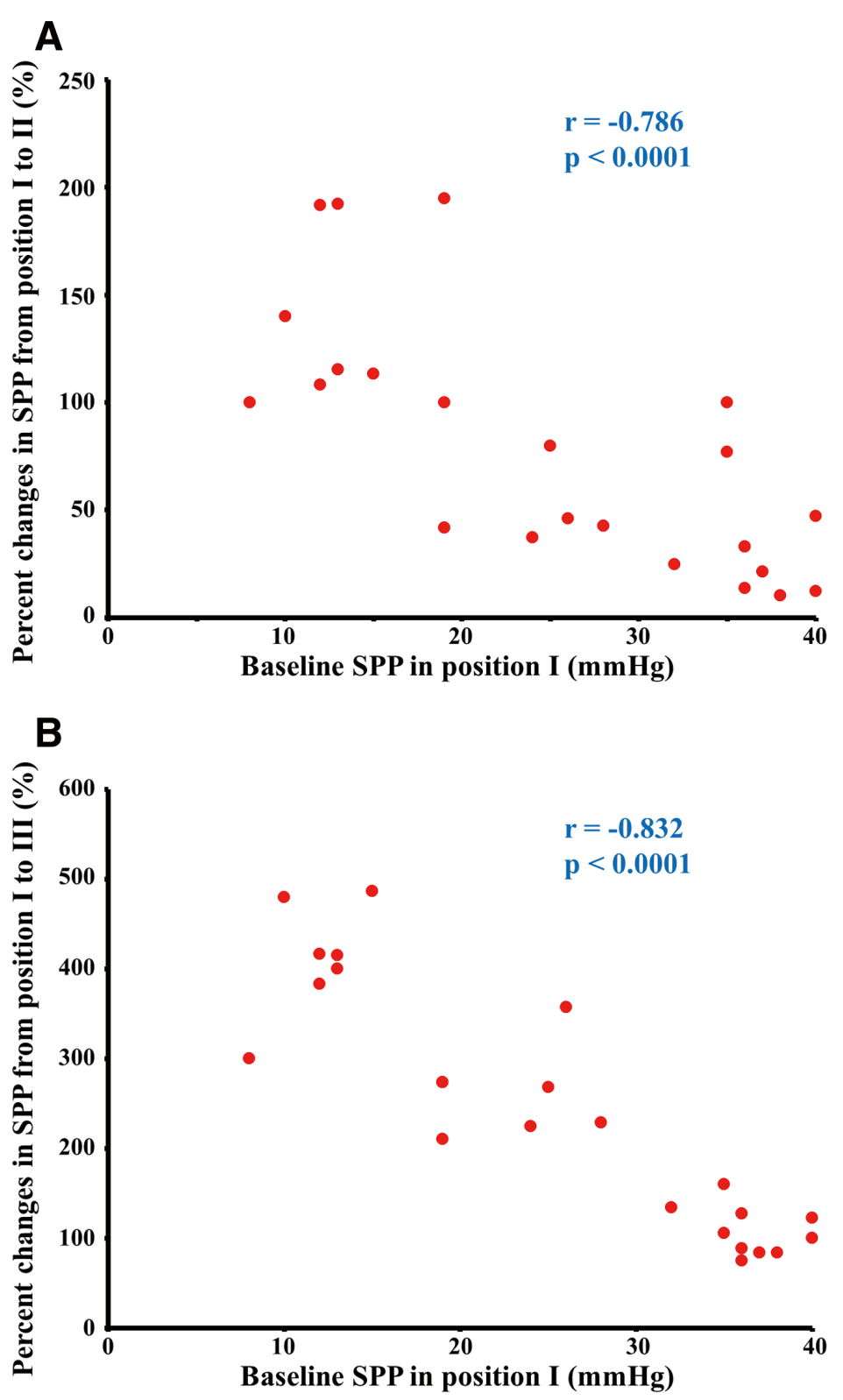

Figure 3. Relationship between the skin perfusion pressure (SPP) in Position I and the percent change in SPP from Position I to Position II or III. There was a significant negative linear correlation between SPP in Position I and the percent change in SPP from Position I to Position II (A; $r=-0.786, P<0.0001)$ or position III $(B ; r=-0.832$, $\mathrm{P}<0.0001)$.

tion (SD), whereas discrete variables are given as absolute values, percentages, or both. Continuous variables were compared using the Friedman test. Dunn's procedure was performed as a post-hoc test. Results were considered statistically significant at $\mathrm{P} \leq 0.05$.

The relationship of the SPP in the supine position to the changed value or changing rate of SPP in other positions was assessed using linear regression and Pearson correlation coefficients.

\section{Results}

The patients' clinical characteristics are shown in the Table. There were 15 limbs in Fontaine Stage III and 9 limbs in Stage IV. The baseline ankle-brachial index was $0.42 \pm 0.24$.

In all patients, SPP increased from Position I to Position II or III, and the average SPP increased significantly from Posi-

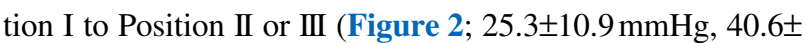
$12.7 \mathrm{mmHg}, 73.4 \pm 17.7 \mathrm{mmHg}$, respectively; $\mathrm{P}<0.01)$. In all patients, SPP values $>30 \mathrm{mmHg}$ were obtained in Position III.

There was a significant negative linear correlation between SPP in Position I and the percent change in SPP from Position I to Position II (Figure 3A; $\mathrm{r}=-0.786, \mathrm{P}<0.0001$ ) or Position III (Figure 3B; $\mathrm{r}=-0.832, \mathrm{P}<0.0001$ ).

\section{Discussion}

Noninvasive measurement of limb systolic pressure is used as the standard for assessing the severity of PAD. However, arterial rigidity associated with medial calcification may interfere with measurement of the ankle pressure. ${ }^{9-11}$ These phenomena are observed more commonly in patients with diabetes mellitus and those undergoing dialysis. Measurement of the pressure at the ankle will not detect isolated obstruction in the more 
distal artery. In contrast, toe systolic pressure can detect distal lesions and is a more useful parameter.,12 However, the presence of skin ulcers, gangrene, or previous digital amputation may preclude measurement of toe pressure. ${ }^{10}$

The measurement of SPP is a noninvasive test that is useful in the assessment of PAD, especially to determine the optimal level for amputation, and to assess critical limb ischemia. ${ }^{1-5}$ Similar to toe pressure, SPP reflects the presence of distal lesions. However, it is not affected by arterial wall calcification. SPP can also be measured in the limb when skin lesions of the toe or digital amputation preclude measurement of toe pressure.

Other noninvasive tests for $\mathrm{PAD}$, such as $\mathrm{tcPO}_{2}$, have been reported to show good results for predicting healing after amputation. ${ }^{13,14}$ One criticism of $\mathrm{tcPO}_{2}$ for predicting amputation wound healing is the wide range of values reported by different investigators as the cutoff for critical ischemia. ${ }^{15}$ Differences in the electrical specifications of the $\mathrm{tcPO}_{2}$ equipment have been implicated. This problem has not been observed with SPP measurement and for this reason SPP is considered as the most useful noninvasive test in patients with severe PAD.

It has been shown that ulcers will heal when SPP is $\geq 30$ $40 \mathrm{mmHg} .{ }^{1-5}$ According to our results, SPP changes significantly depending on the body position at the time of measurement. In all patients, SPP values exceeding $30 \mathrm{mmHg}$ were obtained in Position III, the sitting position with the foot lowered vertically, which is the ideal position for patients with severe PAD from the viewpoint of SPP. Gravity might cause this phenomenon. When we follow a patient using SPP, we have to evaluate the value in the same position each time.

The treatment of severe PAD is challenging. Obviously, revascularization is the prime therapy for patients with severe PAD. In fact, it has been shown that major amputations decrease and limb salvage improves with the development of a revascularization strategy such as open bypass surgery or endovascular intervention. ${ }^{16,17}$ However, revascularization is sometimes impossible because of the poor general condition, infection, severe calcification, or poor distal run-off in patients with severe disease. New therapies, such as gene therapy ${ }^{18,19}$ or Waon therapy, ${ }^{20}$ are actively being studied, but are not yet available for clinical use. Therefore, we need additional therapeutic options for patients with severe end-stage PAD. It has been shown that limb salvage can even be achieved without revascularization in most patients with arterial insufficiency and uncomplicated chronic nonhealing limb ulcers when we treat them only with appropriate conservative management. ${ }^{21}$ Against this background, and based on our results, maintaining Position III, sitting with the foot lowered vertically, may be ideal for the peripheral arterial circulation and a valuable, manageable option for patients with end-stage PAD. We do not usually pay attention to the body position of the patients, but it may be useful to consider positioning as adjunctive management. We found a significant negative linear correlation between SPP in Position I and the percent change in SPP from Position I to Position II or III. In other words, the worse the baseline SPP, the more the patient benefited from changing position.

It is obvious that better SPP values are obtained in Position III, but it is not only SPP that controls the clinical outcome of a critical limb. In the real world, venous return may be interrupted in a sitting position with the foot lowered vertically, and lower extremity edema may be frequently observed. Edema may interrupt the wound healing process in patients with end-stage PAD. Clinical experience in the real world is needed to determine whether this position can be a valuable therapeutic option for end-stage PAD.

\section{Conclusions}

We obtained the best SPP values in Position III, the sitting position with the foot lowered vertically. In other words, this position is ideal for peripheral arterial circulation in patients with severe PAD.

\section{References}

1. Yamada T, Ohta T, Ishibashi H, Sugimoto I, Iwata H, Takahashi M, et al. Clinical reliability and utility of skin perfusion pressure measurement in ischemic limbs: Comparison with other noninvasive diagnostic methods. J Vasc Surg 2008; 47: 318-323.

2. Castronuovo JJ, Adera HM, Smiell JM, Price RM. Skin perfusion pressure measurement is valuable in the diagnosis of critical limb ischemia. J Vasc Surg 1997; 26: 629-637.

3. Adera HM, James K, Castronuovo JJ, Byrne M, Deshmukh R, Lohr J. Prediction of amputation wound healing with skin perfusion pressure. J Vasc Surg 1995; 21: 823-829.

4. Dwars BJ, van der Broek TAA, Rauwerda JA, Bakker FC. Criteria for reliable selection of the lowest level of amputation in peripheral vascular disease. J Vasc Surg 1992; 15: 536-542.

5. Faris I, Duncan H. Skin perfusion pressure in the prediction of healing in diabetic patients with ulcers or gangrene of the foot. $J$ Vasc Surg 1985; 2: 536-540.

6. Lassen NA. Scanning of the distal perfusion in skin and muscle with 133 xenon in estimation of the pressure situation in pregangrenegangrene. Nord Med 1970; 83: 87-88.

7. Castronuovo JJ, Pabst TS, Flanigan DP, Foster LG. Noninvasive determination of skin perfusion pressure using a Laser Doppler. J Cardiovasc Surg 1987; 28: 253-257.

8. Pabst TS, Castronuovo JJ, Jackson SD, Schuler JJ, Flanigan DP. Evaluation of the ischemic limb by pressure and flow measurements of the skin microcirculation as determined by laser Doppler velocimetry. Curr Surg 1985; 42: 29-31.

9. Brooks B, Dean R, Patel S, Wu B, Molyneaux L, Yue DK. TBI or not TBI: That is the question: Is it better to measure toe pressure than ankle pressure in diabetic patients? Diabet Med 2001; 18: 528-532.

10. Tsai FW, Tulsyan N, Jones DN, Abdel-Al N, Castronuovo JJ Jr, Carter SA. Skin perfusion pressure of the foot is a good substitute for toe pressure in the assessment of limb ischemia. J Vasc Surg 2000; 32: 32-36.

11. Quigley FG, Faris IB, Duncan HJ. A comparison of Doppler ankle pressures and skin perfusion pressure in subjects with and without diabetes. Clin Physiol 1991; 11: 21-25.

12. Holstein P, Lassen NA. Healing of ulcers on the feet correlated with distal blood pressure measurements in occlusive arterial disease. Acta Orthop Scand 1980; 51: 995-1006.

13. Ameli FM, Byrne P, Provan JL. Selection of amputation level and prediction of healing using transcutaneous tissue oxygen tension $\left(\mathrm{TCpO}_{2}\right)$. J Cardiovasc Surg 1989; 30: 220-224.

14. Ratliff DA, Clyne CA, Chant AD, Webster JH. Prediction of amputation wound healing: The role of transcutaneous $\mathrm{PO}_{2}$ assessment. $\mathrm{Br}$ J Surg 1984; 71: 219-222.

15. de Graaff JC, Ubbink DT, Legemate DA, de Haan RJ, Jacobs MJ. Interobserver and intraobserver reproducibility of peripheral blood and oxygen pressure measurements in the assessment of lower extremity arterial disease. J Vasc Surg 2001; 33: 1033-1040.

16. Yan BP, Moran D, Hynes BG, Kiernan TJ, Yu CM. Advances in endovascular treatment of critical limb ischemia. Circ J 2011; 75: 756765.

17. Adam DJ, Beard JD, Cleveland T, Bell J, Bradbury AW, Forbes JF, et al; BASIL trial participants. Bypass versus angioplasty in severe ischemia of the leg (BASIL): Multicenter, randomized controlled trial. Lancet 2005; 366: $1925-1934$.

18. Morishita R, Aoki M, Hashiya N, Makino H, Yamasaki K, Azuma $\mathrm{J}$, et al. Safety evaluation of clinical gene therapy using hepatocyte growth factor to treat peripheral arterial disease. Hypertension 2004; 44: $203-209$.

19. Mäkinen K, Manninen H, Hedman M, Matsi P, Mussalo H, Alhava E, et al. Increased vascularity detected by digital subtraction angiography after VEGF gene transfer to human lower limb artery: A randomized, placebo-controlled, double-blinded phase II study. Mol Ther 2002; 6: $127-133$.

20. Miyata M, Tei C. Waon therapy for cardiovascular disease: Innovative therapy for the $21^{\text {st }}$ century. Circ J 2010; 74: 617-621.

21. Marston WA, Davies SW, Armstrong B, Farber MA, Mendes RC, Fulton JJ, et al. Natural history of limbs with arterial insufficiency and chronic ulceration treated without revascularization. J Vasc Surg 2006; 44: 108-114. 